\title{
These Shoes were Made for Talking: Documenting Identity through the Lens of Footwear
}

\begin{abstract}
This article discusses the development of a longitudinal research project Shoe and Tell which is grounded in the principles of visual ethnography. The project was conceived to capture and document the experience of identity for British based teenagers. The teenage years are a significant transitionary period through the human lifecycle, a key time for identity experimentation and formation. In an increasing digital world, perpetuated by social media, this generation have become known for being image conscious, anxious and lonely. This places undue pressure on their sense of self and identity negotiation, and has created assumptions of them being a narcissistic, self-focused demographic. In response to these societal challenges the intention of Shoe and Tell was to bring an insider perspective to teenage identity by documenting, through visual ethnography, the images, real life narratives and experiences of identity from the perspectives of teenagers. While identity has often been examined through the relationship between clothing and individuals this research takes a different, innovative approach by exploring the subject through the lens of footwear. As a worn and ubiquitous object, the shoe has an embodied relationship with its wearer asserting its meaningfulness as a visible expression of self-identity. This article discusses the development of a methodological approach to examine teenage identity. Photography as a form of ethnographic research is used to document and stimulate the narration of experiences and feelings surrounding a young person's sense of self-identity as discussed through the shoes they are wearing. How individuals present themselves and discuss their experience of identity is captured through footwear. What emerges from this study is the value of this innovative visual methodological approach to documenting and understanding identity as it is experienced through a specific transitional life stage.
\end{abstract}

Keywords: Teenagers, Identity, Shoes, Visual Ethnography, Images, Narratives, Embodied Identity

\section{Introduction}

$\mathrm{T}$

The following narrative and image belongs to Maggie, who aged 19, had just arrived at university to start her Fashion degree.

I have always felt rather boisterous and gangly, being that I am $5 \mathrm{ft} 8$, size 7 feet, never very "girly", and felt I needed to show fractured sides of myself to different parts of society. However, this shoe, when I wear it, changes me. It changes the way I carry and look at myself. I am less aware of how I am walking. I feel smaller, more delicate in a way. Maybe it is the Velcro straps, or the innocence of the color white, but they make me feel young, small, very unlike me, but in a wonderful way.

All kids wear Velcro shoes and I was no exception. When my Dad first saw me in these shoes, he said it reminded him of clumsy, giggly, toddler me, wearing my first shoes. I suppose from then I have always enjoyed wearing these shoes for more reasons than one. Not only do they remind me of a time when I was working hard in a grueling internship and a part time job, but they also bring me back to a time when it was just me and my Dad, and I didn't feel the need to edit myself so much, I was just me in my Velcro shoes. (Maggie interview 2017) 


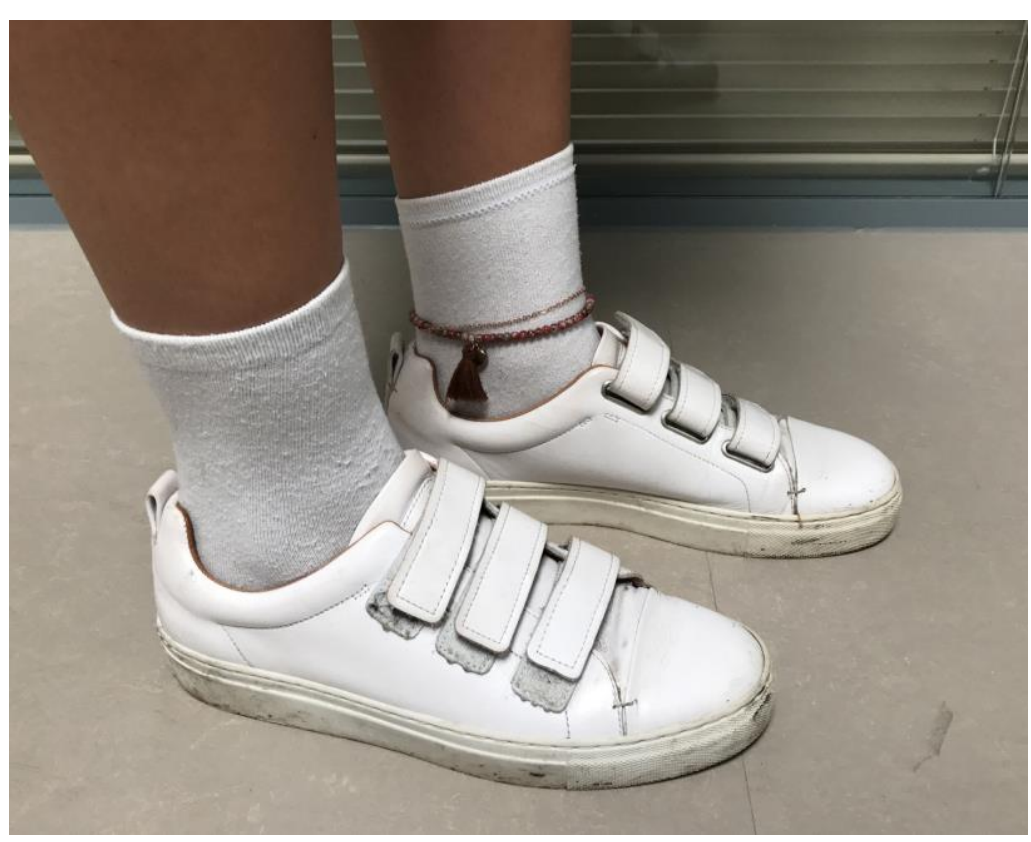

Figure 1: Maggie: My Favorite White Shoes Source: Author's own image, 2017

Maggie had brought these shoes from home to university as they are vested with emotional meaning and life defining memories which are important for her sense of self as she embarked on this new and daunting adventure. Her narrative draws out the transformative power of shoes through how she feels when she wears them. The image and narrative present a sense of individual identity that, for Maggie, is not only visual, but, also emotional. This photograph and narrative extract are from a series of over 150 images and interviews drawn from my research project, Shoe and Tell, which explores identity from the perspectives of teenagers, and, through the lens of their footwear. Shoe and Tell, takes a longitudinal approach to teenage identity and is grounded in the principles of visual ethnography (Pink 2013). The project title "Shoe and Tell" was selected as an emotive expression of the powerful role that shoes play as worn objects in initiating stories around the self. The project focuses on the role of shoes in communicating rites of passage where memories of key moments and transitional stages in an individual's life are embodied through the object's materiality, and experience of wearing.

The research is framed theoretically within material culture where shoes are relational objects of cultural and individual expression. Drawing from Belk (2003) shoes are conceptualized as extensions of self and repositories of memory. Shoes are transformative and through wear, as Maggie's narrative highlights, they have a profound influence on individual and social identity. As worn objects they have an intimate relationship with the body, and how they feel and look on the foot influences the wearer's physicality and their subsequent engagement with the world around them. In turn the shoe's materiality holds the wearer's imprint and embedded within are the memories and experiences of wearing. Grounded in the theory of rites of passage (van Gennep 2019) the study uses shoes and their embodied relationship with the wearer, to investigate identity as individuals transition from childhood to emerging adulthood. A longitudinal approach to the research has enabled the documentation of 
teenage footwear choices and their relationship to experiences of self-identity over an extended timeframe. This has been significant in creating a sociohistorical observation of teenage identity which continues as the project extends.

Through visual ethnography the study documents feelings towards the expression of identity in everyday life, and how individuals negotiate the societal pressures implicit with being a teenager. The taking of photographs of these individuals in their footwear is integral to the research process. The act of photography enables the wearer to perform their identity, and in contrast, the image can become a future provocation for observers to encounter, experience and interpret meaning through visual forms. Drawing from a material culture framework, shoes are active objects through which dialogues around identity are initiated, both photographically and through recorded narratives. The research frames the significance of the photographs within Howes and Cox's account of a new visual anthropology (2016), where images are not secondary to text but are primary documents, invested with meaning. The aim of this article is to discuss the development of the visual methodology that Shoe and Tell employs to interpret the presentation and expression of identity for teenagers, across a longitudinal span. How photography is used to document and stimulate the narration of experiences and feelings surrounding a young person's sense of identity will be explored.

Shoe and Tell focuses on individuals who are referred to as Generation Z, who are the product of the digital age (Parry 2020). This has placed intense stress on these young individuals' self-identity. A UK wide poll carried out by Shout, a monthly teenage lifestyle magazine (Shropshire Star 2019), revealed that over $80 \%$ of teenage girls surveyed found that the pressure to conform to a certain look, compounded by social media, causes anxiety. The act of conforming to a way of being seen whilst ensuring individuality has become integral to the documentation of self-image through social media. Popular opinion leans towards the belief that social media has made society more individualistic (Miller et al. 2016). Further to this, evidence suggests that emerging adults (those born after 1980) have become increasingly narcissistic with a shift in inner values towards image and the importance of being seen (Twenge 2013). The growth of an image conscious society and the subsequent implications including anxiety and loneliness (Turkle 2017) were the triggers for the development of Shoe and Tell, which set out to question how teenagers negotiate the complexity of identity in an image conscious society. The following research objectives were defined:

- To develop an appropriate visual methodology to capture and document individual identities across a transitional life stage

- To explore the role of shoes in communicating identity and experience for a sample of teenagers

- To understand how different individuals, negotiate identity in relation to the transitional life stages from childhood to adulthood

- To reveal emotional responses to feelings around self and identity

In response to the negative portrayal of an image focused generation portrayed in the media, I set out to develop an original research approach, which through visual ethnography would draw out the images and stories that could shed light on the everyday lives of teenagers. The defined visual approach gave an opportunity for teenagers to perform to camera and narrate their individuality in relation to this transitional life phase. This has created a visual record and a platform for each participant to share their own experiences of identity. The intention was to bring a nuanced perspective to the studies of teenagers, and through the power of image and words, to re-imagine identity for these young people. The research considers the existing debates on teenagers and identity and evidences the significance of visual ethnography in social research. Through discussion of the rationale for the research, development of the visual 
methodology and consideration of a selection of the findings from the ongoing study, the article brings forth new insights into the existing debates on teenagers and identity.

\section{Research Context}

Developing the methodology required understanding of the relationship between teenagers and identity and the role of shoes as worn objects in communicating identity. There are a significant number of studies that examine the societal pressures and consequences faced by teenagers in contemporary society. There are also studies that have explored the relationship between teenage clothing consumption choices and self-concept (Piacentini and Mailer 2006, Chattalas and Harper 2007). These perspectives support the continued interest in research on teenagers and identity choices and stimulates the opportunity to design a different methodological approach to the field of research.

Over the last ten years the reported numbers of teenagers facing mental health issues has grown exponentially as has the use of social media platforms such as Instagram and their increasing impact on daily life (Allen 2019). An article featured on The Guardian newspaper's website reported how teenage years, once an enviable moment in life, are now the most challenging time (McVeigh 2016) and certainly this has become a recognized societal issue (Orben 2020). The implications of growing up in a digital world (Twenge 2017) has not only impacted a teenager's relationship to self and other, but also their sense of identity as society has become increasingly image focused (Twenge 2013). Research studies have highlighted the contribution of the digital world, particularly social media usage towards issues of anxiety in adolescents (Jiang 2018). A study conducted by the Royal Society for Public Health in the UK (2017) found that photo sharing platform Instagram was one of the social medial channels most detrimental to teenage mental health and well-being. While social media is a space through which self-identity can be experienced and formed, it can also have negative consequences on the sense of self including loneliness, depression, anxiety and low self-esteem and concerns over body image (RSPH 2017).

Erikson's study of identity formation through life stages (1968) found that the adolescent years (12-24) which comprises the teenage years are significant as pressures and complexities of change can impact an individual's sense of self. The adolescent years are well documented to compromise changes in personality and self-identity (Blakemore 2019) marked by progression towards adulthood. The transition from childhood, through the teenage years, towards emerging adulthood is a key transitional life stage and a time for identity experimentation and formation (Arnett 2010). In the context of the human life cycle the transition towards adulthood is a significant rite of passage (van Gennep 2019) where identity becomes shaped through internal (self) and external (societal) forces. Existing discourse on teenagers and identity further draws out the challenges particularly in the context of gender (Huffaker and Calvert 2005, Engebretson 2006). As the teenage years are key to identity development process, clothing has come to symbolize choices surrounding self-concept relating to peer group influence and individual taste (Muzinich, Pecotich and Putrevu 2003), and as worn objects become valuable tools to examine these issues. Shoe and Tell acknowledges the challenges faced by today's teenagers but through an image led methodology intends to draw out the narratives and experiences around identity with a view to bring forward images and voices of teenagers, bound in time, space and place. The longitudinal scope to the project makes an original and important contribution to the field, as it enables the historical documentation of teenage identity in relation to socio-cultural forces as they evolve over time.

Identity is understood to drive behavior (Reed et al. 2012). While identity was historically defined by stable factors including ethnicity, family, class and geography (González and Bovone 2016), it is far more complex in contemporary society where it has become something aspirational, rather than a given fixed entity (Bauman 1996). Identity is fluid, changeable and 
individualistic (Lifton 1999) and this is particularly apparent in the context of emerging adulthood (Arnett 2010). Teenagers have an almost limitless array of different category labels for identity (Reed et al. 2012). While some of these can be stable factors such as gender and ethnicity, other are more fluid and subjective. While this is complex it brings forth insight into the fascinating, evolving and emotive worlds of young people and their sense of self. As an aspirational force identity enables individuals the opportunity to create a desirable self-image reflecting their feelings and emotions influenced by intrinsic and extrinsic factors (Belk, Mayer and Bahn 1982). This experimental approach to identity formation is most powerful during the teenage years (Marion and Nairn 2011). Exploring individual feelings towards identity can pave the way for understanding also thoughts, feelings and behaviors. However, accessing these feelings presents a challenge which Shoe and Tell sought to address.

Through its aesthetic properties clothing is the most visible representation of identity (Davis 2013) and consequently becomes a significant medium for understanding identity. Ethnographic research has demonstrated that asking individuals to share why they wear what they wear (Miller and Woodward 2011, Woodward 2007, Clarke and Miller 2002) reveals insights into their relationships with self and other. While identity through life's rites of passage is emergent (Baumeister and Muraven 1996), the relationship between what someone wears, and their sense of identity is further complicated as no single outfit can constitute identity alone (Brach 2012). Marion and Nairn's work with teenagers (2011) evidences how clothing practices amongst teenage girls is about a succession of identity experimentations. Clothing is chosen according to specific situational characteristics including peer influence, family and other cultural factors, evidencing the range of forces, both stable and fluid, that influence identity and self-expression. In this context teenage identity exists in a tension between constancy and flux (Marion and Nairn 2011). Rather than drawing from the traditional medium of clothing and its relationship to identity my research takes a nuanced perspective by exploring this phenomenon through the lens of footwear.

As worn objects of material culture, shoes contribute towards the visualization and experience of identity (Hockey et al. 2013). Hockey et al.'s (2014) work on footwear examines their contribution in a life course perspective, establishing the context of my project which considers the role of footwear in communicating identity through the various stages of life's rites of passage, and across a longitudinal span. By focusing on shoes, the study does not deny the meaningfulness and importance of clothing in reflecting identity and recognizes that examining teenage identity, through clothing, could bring alternative perspectives. However, as Brydon (1998) argues shoes, more than clothes, are the most ubiquitous item as they express and mediate meaning upon the individual wearer. The relationship that the shoe holds with the body is significant as its materiality imparts feelings on the wearer, influencing their posture and sense of movement. Through the embodied experience of wear and their aesthetic qualities, shoes, I argue, are important mediums through which identity is represented, experienced and communicated (Entwistle 2000), and it is this which establishes their significance in this research. Within the context of a more image conscious demographic, objects that are worn at the end of the body, become an intriguing method for discussing and documenting identity, as it is perhaps less sensitive than discussing clothing, which draws attention to the body in a different way. Employing a material culture framework, Shoe and Tell examines the choices of shoes worn, their relationship to the self and others, with the intention of understanding how identity is constructed and experienced, revealing deeper insights into the emotive world of teenagers. By drawing out the interrelationship between shoes and wearer the project fleshes out the biographical power of shoes to evoke personal stories, hopes and aspirations that are captured in image, voice, time and place. Longitudinal in its approach the research has created a visual and textual record of teenagers, footwear choices and narratives on identity which continues to evolve as this study progresses. 


\section{The Case for Visual Ethnography}

Existing studies into teenagers and identity have drawn from both quantitative approaches (Chattalas and Harper 2007, Gentina, Shrum and Lowrey 2016) and qualitative studies (Piacentini and Mailer 2004, Marion and Nairn 2011). These qualitative approaches have focused on the complexity of identity formation during this phase of life and the key role of clothing in representing the self. While these studies have revealed issues that are significant to this current research project, in particular the symbolic power of clothing to act as metaphor for visual identities, they have not really delved into how these teenagers feel in clothes and how that can reveal deeper and emotive feelings that are key to understanding identity. Shoe and Tell focuses on identity as being both visual and embodied, communicated through how the shoes look on the wearer but also how they feel. Woodward's ethnography of women and their clothing illustrated how the meaningfulness of clothing stems for its materiality; how clothing feels on the body, has significant impact on the wearer's identity (2007). Ethnographic research on shoes (Hockey et al. 2013) has evidenced their significance in identity formation. Hockey et al's (2013) study examined the relationship between shoes and embodied identity, and, like Belk's earlier research into shoes and identity, discovered them to serve as repositories of memories (2003). Building on this body of work Shoe and Tell seeks to gain insights into the embodied experience of identity for teenagers. The visual ethnographic approach combined with a longitudinal perspective, where teenagers are photographed and interviewed each year, and where possible, selected individuals are interviewed again in later years, brings an innovative approach to the field. The uniqueness of the Shoe and Tell project is its focus on applying an imaged based research within the theoretical frameworks of material culture and rites of passage.

Identity as a visual phenomenon is closely tied to clothing and its role in image creation (Brach 2012). Focusing on a worn object like shoes and employing an image led methodology was therefore key to examining identity in this context. Visual ethnography as an approach that combines taking photographs with narrative interviews (Pink 2013) was identified as an appropriate methodological framework to support Shoe and Tell. The intention was that the photographs would record what these individuals were wearing in terms of specific shoes at a given time, and in so doing they become socio-historical documents of specific aspects of teenage life, as relayed through individual narratives and stories. However, while the project's photographic data has become important for conceptualizing identity from a teenage perspective, these images were not intended to replace the significance of what the teenagers also said about themselves (Pink 2013). The direct quotes from the interviews are significant to the interpretation of the images as it is this combination which draws out the deeper meanings of identity as a visual and embodied experience (Knowles and Sweetman 2004). The visual ethnographic approach has enabled me to capture the display of each teenager's identity through their shoes as cultural products, alongside their narratives of experience and self-image (Holliday 2000). This method brings forth an original body of data to the field of research on teenagers and identity as it includes an ongoing longitudinal study of photographs and narratives, which documents how footwear style choices evolve over time, and also the quotes that represent how teenagers discuss and define identity construction. While visual ethnography has been applied in the study of individuals and their clothing choices (Luvaas 2016), there has been no study that has employed this method to investigate the relationships between teenagers, identity and shoes. In response Shoe and Tell makes a unique methodological contribution to a broad disciplinary field including anthropology, youth studies and fashion theory. 


\section{The Shoe and Tell Methodology}

Shoe and Tell was initiated in 2017 and 150 British based teenagers have been interviewed and photographed, over the past four years. All participants have given their signed informed consent prior to their participation in the study. The age range of these participants was between 16 to 19 years old. The age choice was based upon the fact that these years are particularly transformative in the move from childhood towards adulthood and can include important life defining decisions which include leaving school, going to university and finding a job. The study has included participants through these different life defining moments and considered how these have bearing on their sense of self-identity. The participants came from a range of locations within the UK including London, Nottingham, Manchester, Liverpool and Birmingham. The sampling approach began by drawing from my own diverse personal network to identify parents with teenagers of the right age. Through a process of snowball sampling the participants increased through the teenagers' networks of friends who wanted to join in. There were no specified participant profile characteristics, except age and a willingness to have a photograph taken and to share stories about their shoes, identity and experience. The interviews have been conducted by the author, either with the teenagers individually or within small friendship groups. The small friendship group interviews have involved individual discussions followed with a more conversation group approach. Follow up interviews and photographs after a period of one, two or three years have been undertaken with 40 of the sample. This has been integral in documenting how identity evolves and changes for an individual as they move towards young adulthood. In this context the images and narratives become biographical forms, capturing image and narrative in a specific time. As Shoe and Tell develops it will continue its research with these initial participants, with the intention of creating a visual and textual study of identity through life's rites of passage.

The participants were invited to attend an interview and photograph session and to bring with them a favorite pair of shoes. This could be a special occasion pair or something they wore every day. In many cases they chose to bring multiple pairs to discuss, evidencing the fluid and fragmented nature of identity in contemporary society (Bauman 2013). These interviews generally happened in the home environment. During the Covid-19 in 2020 and 2021 the research was undertaken online in consideration with government restrictions. The initial part of the research process asked the teenager to put on their chosen shoes for the photograph. As Shoe and Tell examines identity through the lens of footwear, the taking of photographs was key to the methodology. The photographs were instrumental to the process as it engaged the research relationship between myself as photographer and the participants, particularly as standing in front of the camera is a familiar activity for this age group (Woodward 2008), bringing a sense of ease to the research encounter. Taking pictures elicited discussion around the transformative nature of the shoes as they were asked to talk how the shoes felt once they were on their feet and how that then linked to sense of identity through the later stages of the interview. The putting on of the shoes and the preparing for the image, commonly termed between Shoe and Tell participants as "striking a shoe pose" is part of the teenager's narrative. It is only their feet in the shoes that are taken for the photograph. While this was important in ensuring the anonymity of these individuals it has also been impactful for the interpretation of meaning from the images where it is not possible to see who the wearer is. The act of taking the photograph as well as the final image have both been significant to the creation of research data. The direct quotes that support the images are integral to drawing out each teenager's feelings around identity.

Following the photograph came the interview which was designed to flow conversationally through a semi-structured approach. This opened with them being asked to describe their shoes and why they had chosen to bring them to the interview. Perhaps a limitation of the research 
approach was that the teenagers most commonly chose a pair of shoes to discuss that had positive experiences and memories. On reflection this would not always allow an alternative perspective to their sense of self-identity. However, the interviews were instrumental in sensitively drawing out wider feelings about the self which sought to overcome this potential limitation. The interviews created discussion around the meaningfulness of the shoes, experiences of wear, how they came to own them and what they felt the shoes said about their identity. Recounting previous occasions when they had worn the shoes was a fascinating insight into the significance of memories and life experience in framing identity. Focusing on the materiality of the shoes, it was intriguing to watch the teenagers describe how the scuffs on the shoe's surface or the remnants of mud embedded on the soles were embodiments of meaningful moments in their lives. While the photographs represent the traces of wear, the supporting narratives reveal the meaningfulness of these traces as material representations of life experience and how that contributes to their biography and sense of self-identity. Marsh's image of her beloved walking boots in figure 2, and the direct quote evidence how meaning is embedded through wear and the patina of the object.

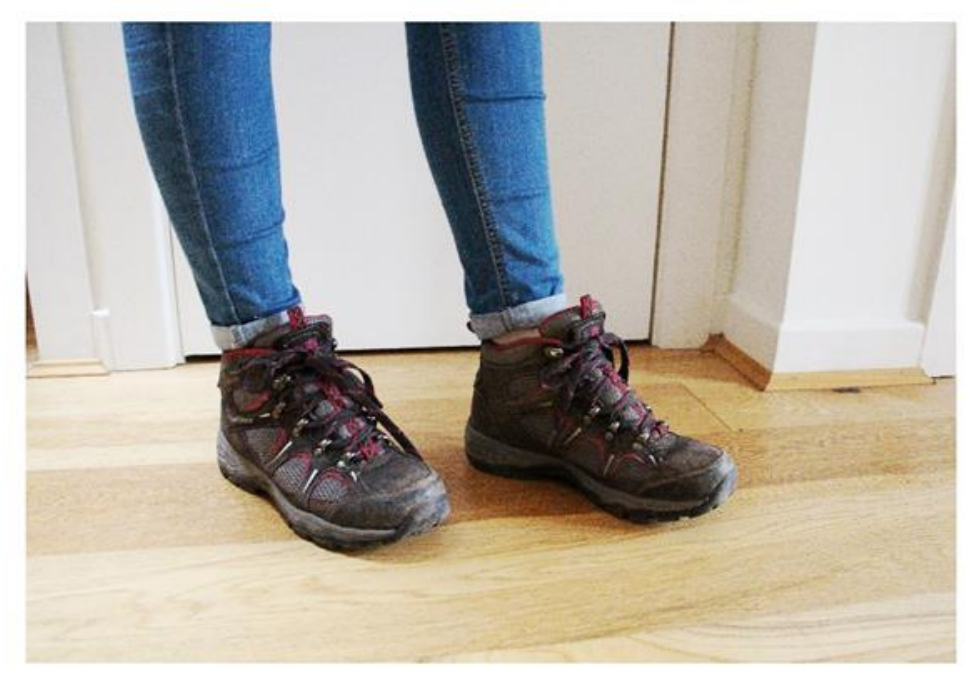

Figure 2: Marsh's Muddy Walking Boots Source: Author's own image, 2017

These are my walking boots that I've had five or six years. I bought them when I was doing Duke of Edinburgh. I have worn them all over the UK, they have mud on them, cow dung, sick, everything on them. They are definitely not my favorite pair, but they remind me of a lot of fun stuff. (Marsh interview 2017)

Sophie's image (figure 3) and narrative from 2021 also demonstrates the emotive meaning that the traces of wear on her shoes have for defining her life narrative. These Reebok sneakers are reflective of her first year at university, a time before the huge challenges and changes to her university experience which were brought on by Covid-19. Reflecting on those moments when life was unrestricted have become significant in framing what matters most to her at this point in her life as a final year student. 


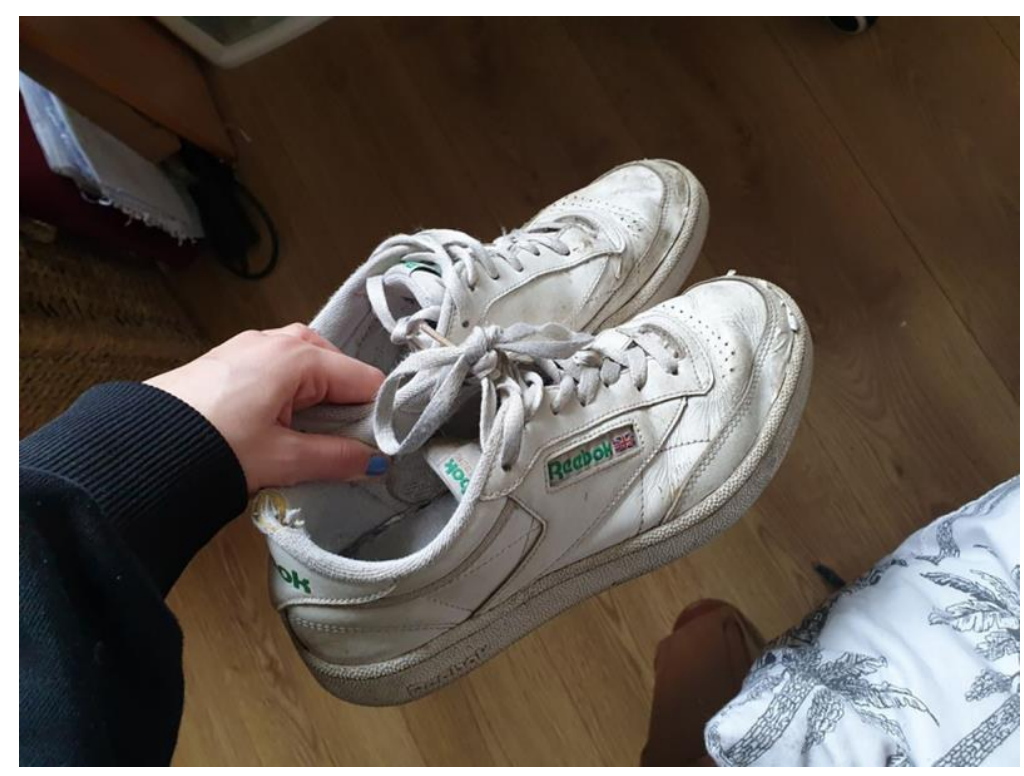

Figure 3: Sophie's Treasured Reeboks

Source: Author's own image, 2021

I bought them in first year, I wear them pretty much every day still they are completely battered (so grim) but it means they are molded to my feet. They have two holes in the bottom which I've superglued so I can't wear them in the rain, but they have sentimental value after wearing them to Uni all the time and countless nights out, wearing them in New York and on holiday. They are a part of my identity, so I just feel myself when I wear them, they feel like home. (Sophie interview 2021)

Asking how the participants feel in their shoes in the interviews has revealed a myriad of different emotions for these teenagers. Through their footwear choices they have narrated a range of emotions which include the importance of individuality, the need to fit into a friendship group, the significance of being comfortable, feeing grown up and sometimes cool. These answers were instrumental for opening up deeper dialogues to what influenced them as individuals, whether that be internal factors or external forces including societal expectations, or in most cases a combination which fluxed according to time and situation. The emotions they defined often leaned towards more positive characteristics which may not give a complete picture of each teenagers' experiences of identity. However, interviews have revealed the deeper insights that suggest why it is important for the individual to feel cool, confident and empowered amongst other emotions. While the images alone may stimulate specific assumptions around teenage identity, for example following the trend for wearing branded sneakers, or investing in the first high heels as a symbol of womanhood, across a longitudinal span, they can provoke deeper discussions around identity as an embodied phenomenon.

In order to consider the wider impacts of this visual ethnographic approach I took a series of images and direct quotes from the first 60 participants and showed them in a small exhibition in Nottingham, UK. The intention was to move away from some of the assumptions about teenagers, discussed earlier in this article, and instead empower the teenage voice by celebrating identity in their own words and images. Each photograph was supported by a direct quote from their narrative which responded to the question what do these shoes say about you. Exhibition visitors were asked to reflect on something that they had gained from the exhibition. These were written on a card tag which was then added to a shoe tree (figure 4). During the three days of 
the exhibition over 180 tags had been attached to the tree. These were responses to what shoes meant to the visitors and something they had learnt about teenagers. Responses included:

'I never really felt that shoes could tell stories before. It seems they stand for something". (visitor 10 2017).

"I am more aware now about young people, and how they choose to present their identity" (visitor 95 2017).

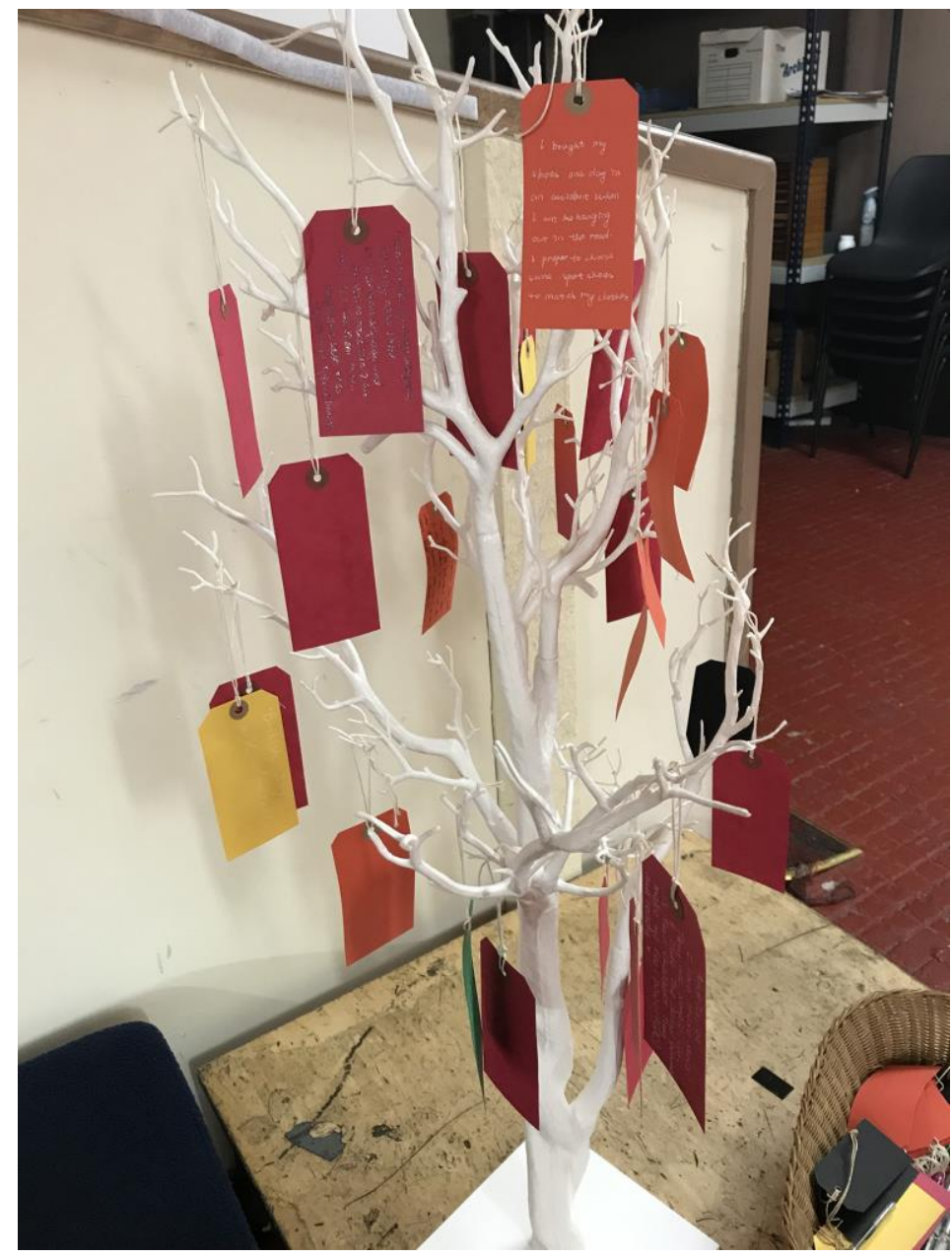

Figure 4: Shoe Tree

Source: Author's own image 2017

In addition to the extensive data gathered from the visual ethnography for Shoe and Tell, these responses to the images and quotes evidence the value of this methodology for provoking insights into teenagers, shoes and identities from a broader perspective. Images are not only mediums through which identity is communicated by the photographed individual but also enable observers to view and re-interpret meaning. The application of this visual methodology has shown that images have agency (Gell 1998) and are dialogic as they enable individuals to narrate their experiences of self, while being an object through which others can re-imagine relationships between identity, style and social context. The photographic data collected to date 
demonstrates that identity is not static, and the image enables the experience and interpretation of its fluidity for the photographed, and for the viewer. Through this research the image becomes central to the experience of self and other and initiates a creative approach to understanding identity.

As Shoe and Tell continues a number of participants from the first phase of research in 2017 have been re-interviewed in either a one, two, or three year timeframe. This usually complements a change in their life experience which has included starting university and graduating. The research process is structured in the original format but probes deeper if changes towards identity and experience are narrated. The photographs taken record different stages in that individual's biography and with support of the narratives, they document how shoe choice represents a different expression of self. In this sense the theoretical framework of rites of passage which acknowledges the impact that different life stages can have on individuals and their sense of self as life presents new thresholds to cross (van Gennep 2019), supports the visual ethnography. Belk (1998) claimed that identity is structured chronologically as a continuous story of self. Drawing from a material culture framework Shoe and Tell reveals this story of identity as expressed through the relational role of shoes. While the images have become visual representations of the teenage participants, they have also become valuable records of the image of teenage identity located in a specific time.

\section{Findings}

The interviews last between 60 to 120 minutes. They are audio recorded and transcribed verbatim. A thematic analysis is applied to interpret the interview narratives. The photographs have been categorized across various themes. This has included linking images of shoe choice to different perspectives on identity, for example those that are chosen by the teenager to assert individuality against those who have chosen to wear something because their friends have it. An unexpected category was the proliferation of images that were of perfectly white clean sneakers versus the very muddy, worn through shoes. These images resonated particularly with attitudes towards purity and a child-like identity (white shoes), as evidenced in Maggie's opening narrative, and memories of wear in relation to life experience, including specific occasions (dirty shoes). Further analysis of the images reveals that sneakers are a preferred footwear choice across genders. This fits with the growing dominance that sneakers have in the footwear market and their cultural status as objects of desire (Kawamura 2016). While most of the shoes documented have been sneakers, there are identifiable shifts in the type of brands and styles favored, indicative that teenage identity is often influenced by popular culture and fashion trends. While the overall findings from this study are extensive the paper will focus on some key insights from the ethnographic data which serves to emphasize the value of the visual methodology, and a sense of teenage identity across a specific timeframe.

\section{If the Shoe Fits....}

The research process has demonstrated the powerful role that shoes have with this demographic for communicating narratives around identity. As worn, embodied objects shoes have an integral role in the representation of identity (Entwistle 2015). In the context of this project identity is taken to be intrinsically linked to image which reflects the emotive characteristics and feelings of a person (Brach 2012). The project data presents the image of the teenagers and how this is communicated through narrative. This deepens interpretation beyond the aesthetic exterior of the worn shoe through to experience of an embodied identity. 
Simmel (1957) theorized fashion as a tension between individuality (standing out) and conformity (fitting in). Analysis of the data has evidenced how this paradoxical perspective influences the sense of identity for many of the profiled teenagers. Ella and Matilda (figures 5 and 6) were both 16 years old and good friends at the time of interview. Their individual narratives expressed that for them being individual and not like others was key to their identity construction. However, their images have a strong similarity as they wear the same brand of Converse sneakers and black athleisure trousers with a three white stripes design. While their images make them seem strikingly similar what sets them apart is their sense of individuality which reflects their feelings and experiences. Individuality through style is complex, and in relation to image it is often difficult to see where difference is expressed. Woodward's work on the myth of street style (2009) found that individuality is often not invested in the individual garments worn, but through the assembling of the look and its personal significance to the wearer. Ella and Matilda's quotes are their response to why these shoes are meaningful to them. Their words invest deeper meanings to the images as they demonstrate the complexity of individuality for these teenagers and that what it truly means runs much deeper than image. Ella and Matilda's desire for individuality was not unique and the paradoxical nature of individuality versus conformity appears to be a constant influence for teenage self-identity.

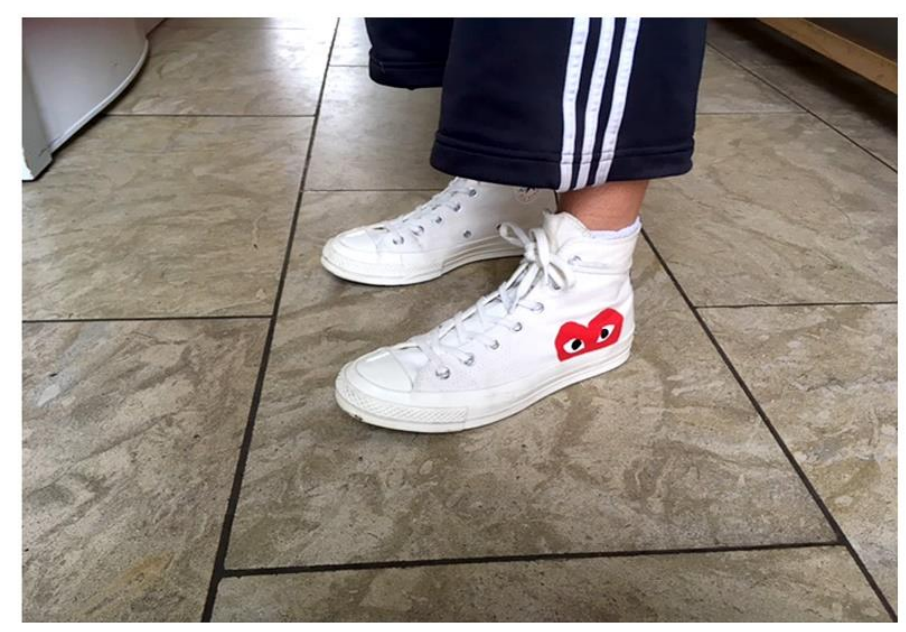

Figure 5: Ella in Converse

Source: Author's own image 2018

I feel individual, comfortable and confident. I prefer to be different and dislike being the same as others (Ella interview 2018) 


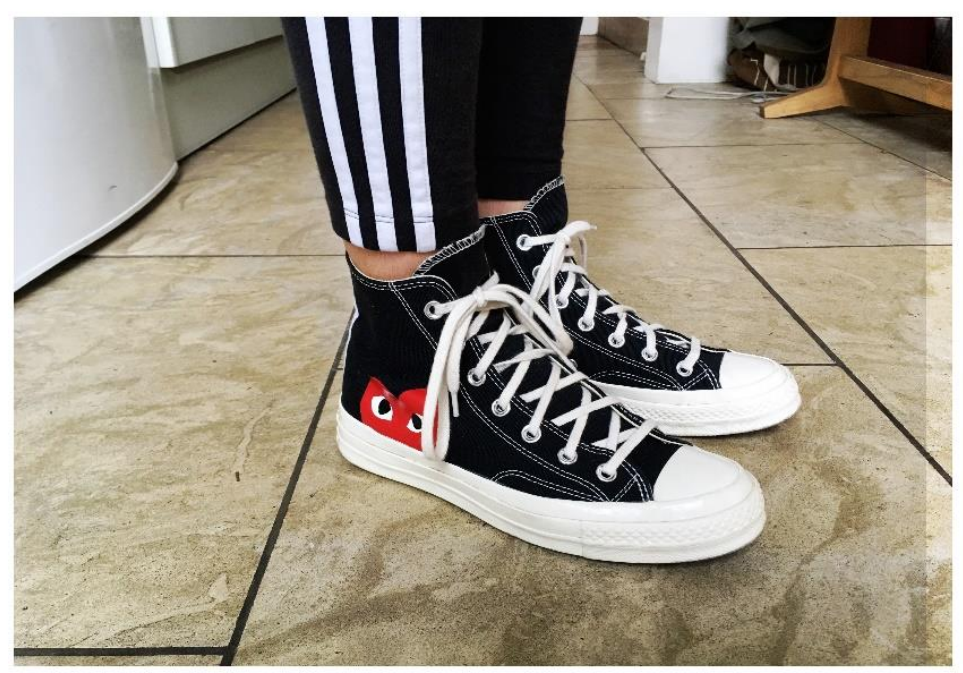

Figure 6: Matilda in her Converse

Source: Author's own image 2018

These shoes are practical, comfortable and make me feel different to others (Matilda interview 2018)

The desire to assert individuality can align with the psychological transformation inherent in moving from childhood towards adulthood (Arnett 2010), which enables greater freedom for identity experimentation. Reflecting on her favorite designer high heels Ellie (aged 18) states the importance of their role in framing individuality but she goes further to draw out how wearing them makes her feel.

I feel very empowered when I wear them, I feel confident and wearing them drives me to work harder to buy more. Physically as well they elongate my legs and make them seem more toned so that gives me a confidence boost. The sparkles also make them unique to other pairs therefore they feel more unique. (Ellie interview 2021)

Ellie's words are powerful as they demonstrate how the shoe is impacting her physicality. She feels they make her look better, more toned, and in response she feels better. Her narrative is an example of how behind the positive experience of these shoes lies a lack of self-confidence and need to feel better about herself. These narratives demonstrate that individuality is not just how the teenagers wish to be seen but more importantly how they want to feel. A striking insight was that when shoes fulfil a need they continue to be worn and often become treasured items never to be disposed of. For James his battered, black Vans are treasured objects from his teenage years, that he cannot bear to part with. 
I love my battered Vans sneakers. I have worn them to death and have so many memories, happy and stressful at times. They have always been with me. (James interview 2020)

There is an interesting contrast between the favorite pair that radiates uniqueness against the loved and worn to death that are valued more for their functionality rather than appearance. How sense of identity fluxes within individual narratives and through the nature of the shoes captured through photographs is a compelling insight from the research. It clearly resonates with Belk's work on shoes as extension of self (2003) and their role in communicating embodied identity (Hockey et al. 2013). While the data from Shoe and Tells adds to this field of research it contributes an original perspective through the images which tell the story of self through the image and through the materiality of the worn patina of the shoes.

\section{The Biographical Self}

Charlotte, like Maggie, was in her first year at university, but as it was spent mostly in lockdown due to the Covid-19 pandemic, she chose to discuss a pair of boots that defined her first few months in Nottingham, before further restrictions halted her university experience These boots which she defined as her 'battle boots'(figure 7) are vested with memories from her first few weeks at University, while also reflective of her sense of who she is. They had become important in shaping her self-identity as she embarked on a new chapter in life as a student. Coming to university is a significant rite of passage and many of the teenagers interviewed have been at the start of this new journey. What has been compelling in this phase of research was how many, like Charlotte and Maggie, chose to discuss shoes that defined something important to their past life and for framing the next stage. Giddens (1991) has conceptualized the reflexive project of the self where identity becomes an ongoing narrative of the self's biography. The research with these teenagers has been important in evidencing the biographical role for shoes in the life of teenagers. What is key is how significant it is to wear an object that is invested with meaning and memory that supports the emotional transition to the next phase of life. 


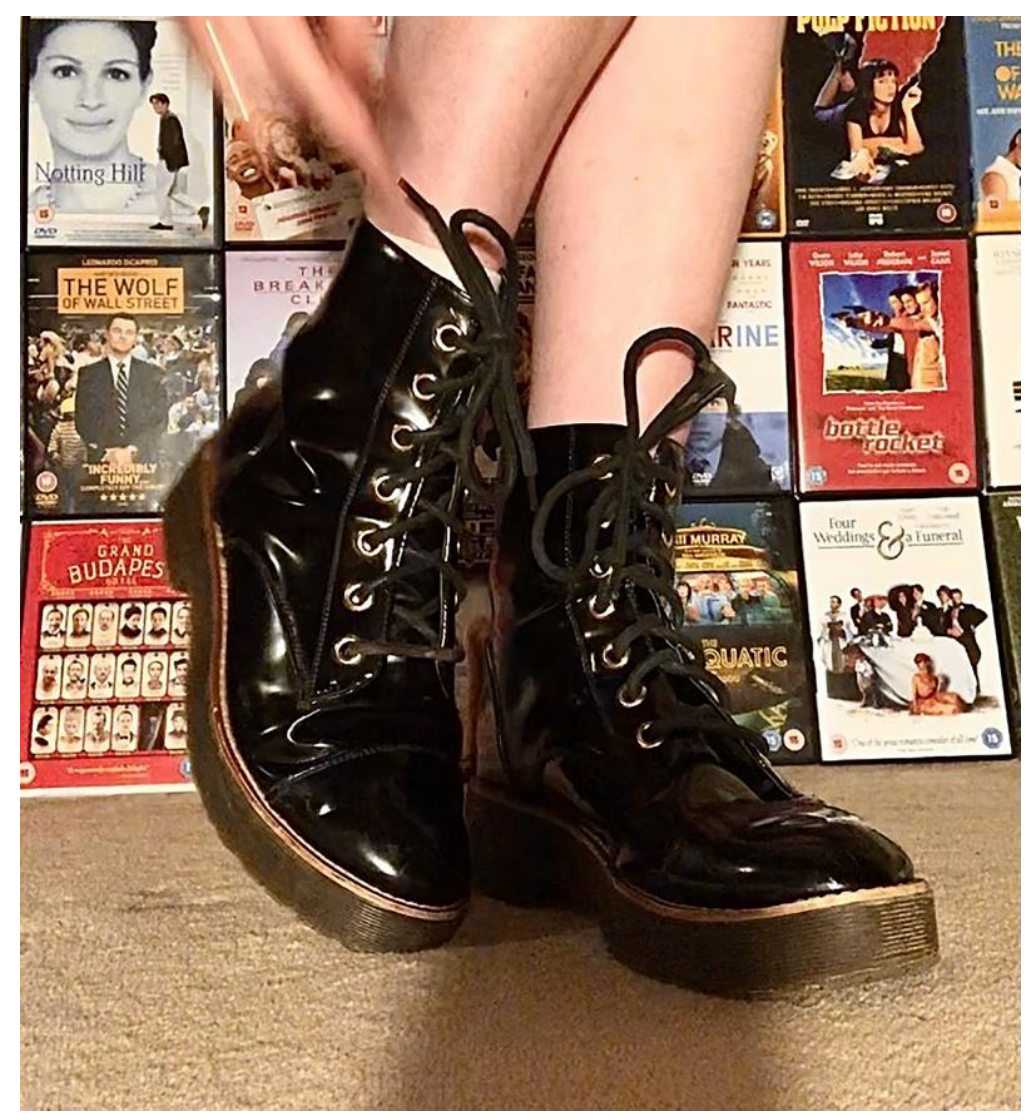

Figure 7: Charlotte's Battle Boots Source: Author's own image 2021

The pair of shoes that bonded me and my flat mate, (now close friend) Millie, on our first scary, awkward charity shopping quest in Nottingham. Having only known her a day, she found me these... in my size... for $£ 4$. It's fair to say that these unmatched shopping skills, have made us partners in crime, and not helped our shoe hoarding obsession. I've worn them through every Uni adventure so far! They've met new people with me, explored a new home, seen late nights and early mornings, danced with me, witnessed me laugh and cry and caused me to fall over a lot! So, they mean a great deal to me, and make the blisters worth it, for the memories that they hold. (Charlotte interview 2021)

The longitudinal nature of the data emphasizes how values shift over the teenage years as individuals move closer towards adulthood. This has a bearing on shoe choice and its relationship with self-expression. The narratives from Marsh, aged 17 (figure 8) and 19 (figure 9) are intriguing. Aged 17 Marsh's favorite shoes were a pair of heeled over the knee boots. She explains their significance: 


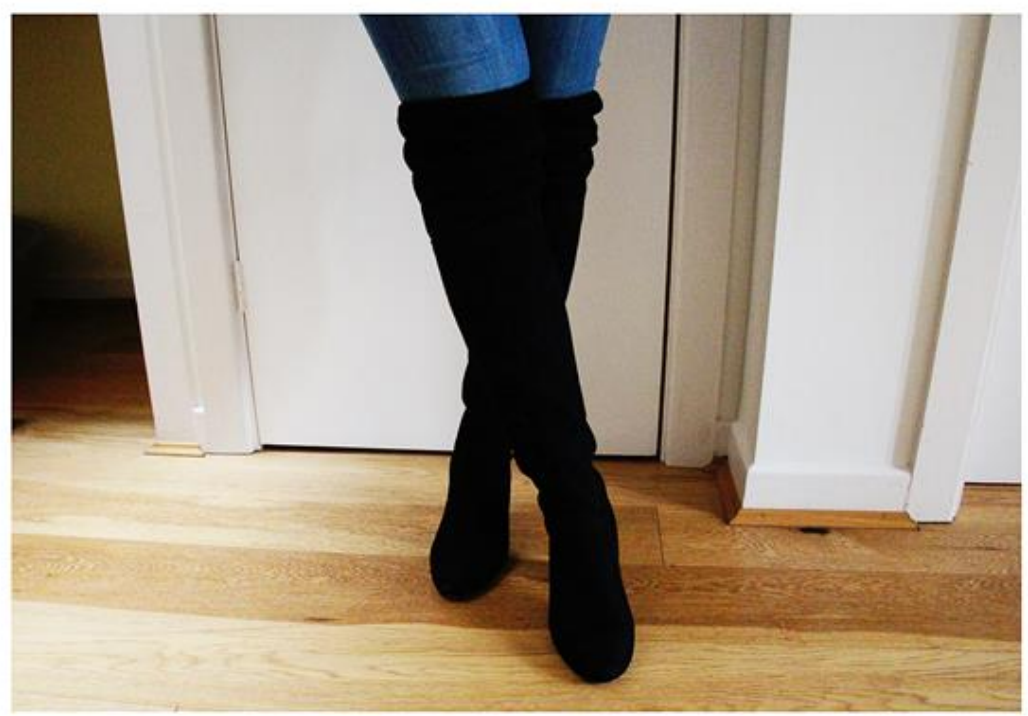

Figure 8: Marsh's Fancy Boots Author's own image, 2017

These are definitely me because they are very fancy. When I put them on, they make me feel like a put together woman, confident, fancy and a lot taller, which is always helpful when you are $5 \mathrm{ft} 2$. A put together woman means you walk around; you know what you are doing and your clothes and shoes reference that. You walk in a place you feel good in yourself, you feel confident, like your shoes can conquer the world. (Marsh interview 2017)

At the time Marsh was at school and considering her next future step at university. I visited Marsh again after two years as she was just completing her first year at university. What mattered to her in terms of shoe choice and identity expression was quite different:

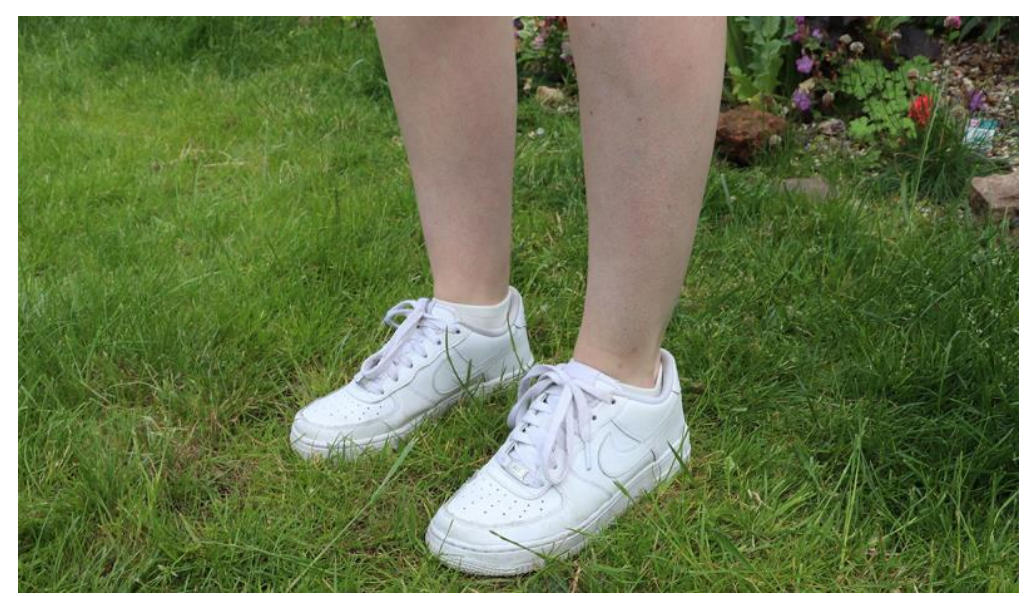

Figure 9: Marsh's Nike Air Force Author's own image, 2019 
I bought these Nike White Air Force in my first term at Birmingham Uni. Everyone else was wearing them and I just wanted a pair for myself. I love the whiteness of them, and I always keep them clean. I keep them white with baby wipes and would never wear them out to a club. I bought them because it is what my friends have, and they feel like me. (Marsh interview 2019)

Marsh's narratives and images reflects again how identity fluxes between individuality and conformity (Simmel 1957) and in the context of rites of passage, they evidence how individuals are in a constant state of becoming (Bergson 1974). Consistent though is the desire to wear things that feel right. The research with teenagers, particularly in their first year of university documents that sneakers are a shoe of choice. Another participant Grace stated:

I brought lots of heels to university in my first term, but I didn't wear any of them and ended up buying sneakers. I think the trainer look for me was about fitting into Uni, a kind of university identity. (Grace interview 2019)

While the strong similarity of sneakers worn by teenagers across the longitudinal span of the project so far, creates a uniformity in identity for some teenagers, through this they enable the achievement of the feeling of individuality. As Marsh states with reference to her Nike Air Force, "they feel like me". While the photographs visualize am image of the self, the quotes reinforce that identity is not only aesthetically expressive it is embodied. It is how the worn shoes feel on the wearer that evokes the experience and expression of identity.

The study findings detail the importance of memories that shoes can hold for the individuals. There were many pairs of shoes that were discussed which were covered in mud which could not be cleaned as that might erase their meaningfulness.

I love my dirty black vans. There is a hole in the top and the sole, but they are a treasured pair. So many memories of times worn, festivals attended, nights out with friends. When I wear them, I think about all those great times. I will keep them forever. (Chris interview 2019)

Chris's narrative reinforces how important memories are for defining life experience for teenagers. While it is not a visual representation, the materiality of the shoe holds those meanings and memories within the aesthetic exterior. Shoes are more than just images of identity; they are expressions of the biographical self. The process of photographing the individuals in the shoes has enabled a reflection on their meaning and role in defining the past, present and future sense of self for these teenagers.

\section{Implications and Conclusion}

The images and interview narratives have enabled the researcher to flesh out the complexity of identity within the teenage demographic. The visual ethnography has drawn out the tensions that underpin a teenager's sense of self as they veer between the desire to be individual whilst conforming to societal expectations including peer influence. The existing debates on teenagers have presented a generation that are too often plagued by the pressures of image, anxiety and loneliness. Shoe and Tell, in contrast, has produced a body of images and narratives which 
draws out a different perspective. While it is clear teenagers are concerned about image and how they are perceived, their life experiences and relationships with others are significant in creating an evolving and compelling biographical self. Identity runs deeper than image and the worn shoe opens the possibilities of exploring how it is constructed and narrated as an emotion and feeling.

In this article I have presented the development of a methodological approach to explore and understand teenage identity, alongside the discussion of some of the findings from the first four years of the project. The study gives a detailed view of the perspectives from British teenagers and as such does not intend to present a generalised argument of how all teenagers may experience self-identity. However, the insights and methodological approach are significant to the enquiry of teenagers and their sense of self beyond geographical boundaries. As the project is longitudinal and continues this article gives a flavour of the richness of the findings, which undoubtedly will change as society and the pressures faced by teenagers continue to evolve. Shoe and Tell sets out to answer the research question of how teenagers negotiate the complexity of identity in an image conscious society. The images and narratives evidence that the negotiation of identity is in constant flux through different life stages and situations. In line with the views of a postmodern society (Lifton 1999) identity is fragmented and fluid, enabling a breadth of reference points which can inspire and influence teenagers in their self-expression. The 150 photographs which have been taken to date bring an intriguing visual record of teenage footwear choices over a specific timeframe. While 135 of these are sneakers it would be misleading to make generalized observations of what that says about teenagers. Despite the commonalities in the findings between individuality and conformity, memories and life experiences, the narratives evidence that individuality is key to teenage identity construction. Subjectivity and biography are the underpinning metaphors for identity and through this individuality is realized.

Shoe and Tell has employed an original methodological approach to the field and its innovative outcomes lie in the data set of images and narratives that are theoretically grounded within material culture and rites of passage. The study's analysis of the teenager's experience of identity combined with the visual documentation of the look is significant in presenting a longitudinal perspective of teenagers by drawing out the emotional experience of identity in relation to self and society.

\section{Acknowledgements}

The author would like to thank all the teenagers who gave their consent to participate in the study. I thank them for letting me into their lives and sharing their emotive and powerful stories.

\section{REFERENCES}

Allen, Summer. 2019. "Social Media's Growing Impact on Our Lives”. Accessed May 29, 2021. https://www.apa.org/members/content/social-media-research.

Arnett, Jeffrey Jensen. 2010. "Emerging Adulthood (s)." Bridging Cultural and Developmental Approaches to Psychology. New Syntheses in Theory, Research, and Policy: 255-275. https://doi.org/10.1093/acprof:oso/9780195383430.003.0012.

Bauman, Zygmunt. 2013. Liquid Modernity. Cambridge: John Wiley \& Sons.

Baumeister, Roy F., and Mark Muraven. 1995. "Identity as Adaptation to Social, Cultural, and Historical Context." Journal of Adolescence 19 (5): 405-416. https://doi.org/10.1006/jado.1996.0039.

Belk, Russell W. 2003. Shoes and Self. Advances in Consumer Research 30: 27-33.

Belk, Russell W. 1989. "Extended Self and Extending Paradigmatic Perspective." Journal of Consumer Research 16 (1): 129-132. https://doi.org/10.1086/209202. 
Belk, Russell W., Kenneth D. Bahn, and Robert N. Mayer. 1982. "Developmental Recognition of Consumption Symbolism." Journal of Consumer Research 9 (1): 4-17. https://doi.org/10.1086/208892.

Bergson, Henri. 1974. The Creative Mind. New York: Citadel Press.

Blakemore, Sarah-Jayne. 2018. Inventing Ourselves: The Secret Life of the Teenage Brain. New York: Doubleday.

Brach, Ann Margaret. 2012. "Identity and Intersubjectivity." In Identities Through Fashion: A Multidisciplinary Approach, edited by Ana Marta González and Laura Bovone, 48-64. London: Bloomsbury.

Brydon, Anne. 1998. "Sensible shoes". In Consuming Fashion: Adorning the Transnational Body, edited by Anne Brydon and Sandra Niessen, 1-22. Oxford: Berg.

Chattalas, Michael, and Holly Harper. 2007. "Navigating a Hybrid Cultural Identity: Hispanic Teenagers' Fashion Consumption Influences." Journal of Consumer Marketing 24 (6). https://doi.org/10.1108/07363760710822936.

Clarke, Alison, and Daniel Miller. 2002. "Fashion and Anxiety." Fashion Theory 6 (2): 191213. https://doi.org/10.2752/136270402778869091.

Davis, Fred. 2013. Fashion, Culture, and Identity. Chicago: University of Chicago Press.

Engebretson, Kathleen. 2006. "Identity, Masculinity and Spirituality: A Study of Australian Teenage Boys." Journal of Youth Studies 9 (1): 91-110. https://doi.org/10.1080/13676260500523663.

Entwistle, Joanne. 2015. The Fashioned Body: Fashion, Dress and Social Theory. Cambridge: John Wiley \& Sons.

Entwistle, Joanne. 2000. "Fashion and the Fleshy Body: Dress as Embodied Practice." Fashion Theory 4 (3): 323-347. https://doi.org/10.2752/136270400778995471.

Erikson, Erik H. 1968. Identity: Youth and Crisis. New York: WW Norton \& company.

Gell, Alfred. 1998. Art and Agency: An Anthropological Theory. Oxford: Clarendon Press.

Gentina, Elodie, L. J. Shrum, and Tina M. Lowrey. 2016. "Teen Attitudes Toward Luxury Fashion Brands from a Social Identity Perspective: A Cross-cultural Study of French and US Teenagers." Journal of Business Research 69 (12): 5785-5792. https://doi.org/10.1016/j.jbusres.2016.04.175.

Giddens, Anthony. 1991. Modernity and Self-identity: Self and Society in the Late Modern Age. Cambridge: Polity Press.

González, Ana Marta, and Laura Bovone. eds. 2012. Identities Through Fashion: A Multidisciplinary Approach. Oxford: Berg.

Hockey, Jenny, Rachel Dilley, Victoria Robinson, and Alexandra Sherlock. 2014. "The Temporal Landscape of Shoes: A Life Course Perspective." The Sociological Review 62 (2): 255-275. https://doi.org/10.1111\%2F1467-954X.12154.

Hockey, Jenny, Rachel Dilley, Victoria Robinson, and Alexandra Sherlock. 2013. "Worn Shoes: Identity, Memory and Footwear." Sociological Research Online 18 (1): 128142. https://doi.org/10.5153\%2Fsro.2897.

Holliday, Ruth. 2000. "We've Been Framed: Visualising Methodology." The Sociological Review 48 (4): 503-521. https://doi.org/10.1111\%2F1467-954X.00230.

Howes, David, and R. Cox. 2016. "Sensing Cultures: Cinema, Ethnography and the Senses." In Beyond Text? Critical Practices and Sensory Anthropology, edited by Rupert Cox, Andrew Irving and Christopher Wright, 173-188. Manchester: University of Manchester Press.

Huffaker, David A., and Sandra L. Calvert. 2005. "Gender, Identity, and Language Use in Teenage Blogs." Journal of Computer-mediated Communication 10 (2). https://doi.org/10.1111/j.1083-6101.2005.tb00238.x.

Jiang, JingJing, 2018. "How Teens and Parents Navigate Screen Time and Device Distractions." $\quad$ Accessed May 2021. 
https://www.pewresearch.org/internet/2018/08/22/how-teens-and-parents-navigatescreen-time-and-device-distractions/.

Kawamura, Yuniya. 2016. Sneakers: Fashion, Gender, and Subculture. London, New York: Bloomsbury Publishing.

Knowles, Caroline, and Paul Sweetman. 2004. Picturing the Social Landscape: Visual Methods and the Sociological Imagination. London: Routledge.

Lifton, Robert Jay. 1999. The Protean Self: Human Resilience in an Age of Fragmentation. Chicago: University of Chicago Press.

Luvaas, Brent. 2016. Street style: An Ethnography of Fashion Blogging. London, New York: Bloomsbury Publishing.

Marion, Gilles, and Agnes Nairn. 2011. "“We Make the Shoes, You Make the Story" Teenage Girls' Experiences of Fashion: Bricolage, Tactics and Narrative Identity." Consumption, Markets and Culture $14 \quad$ (1): $29-56$. https://doi.org/10.1080/10253866.2011.541181.

McVeigh, Tracey, 2016. It's Never Been Easy Being a Teenager. But is This Now a Generation in Crisis? Accessed May 29, 2021. https://www.theguardian.com/society/2016/sep/24/teenagers-generation-in-crisis.

Miller, Daniel, Jolynna Sinanan, Xinyuan Wang, Tom McDonald, Nell Haynes, Elisabetta Costa, Juliano Spyer, Shriram Venkatraman, and Razvan Nicolescu. 2016. How the World Changed Social Media. London: UCL press.

Miller, Daniel, and Sophie Woodward, eds. 2011. Global Denim. Oxford: Berg.

Muzinich, Natalie, Anthony Pecotich, and Sanjay Putrevu. 2003. "A Model of the Antecedents and Consequents of Female Fashion Innovativeness." Journal of Retailing and Consumer Services 10 (5): 297-310. https://doi.org/10.1016/S0969-6989(02)00060-7.

Orben, Amy. 2020. "Teenagers, Screens and Social Media: A Narrative Review of Reviews and Key Studies." Social Psychiatry and Psychiatric Epidemiology 55: 407-414. https://doi.org/10.1007/s00127-019-01825-4.

Parry, Caroline, 2020. Meet the Next Consumer: How Gen Z Are Taking on a New Reality. Accessed May 26, 2021. https://www.thedrum.com/news/2020/11/03/meet-the-nextconsumer-how-gen-z-are-taking-new-reality.

Pink, Sarah. 2013. Doing Visual Ethnography. London: Sage.

Piacentini, Maria, and Greig Mailer. 2004. "Symbolic Consumption in Teenagers' Clothing Choices." Journal of Consumer Behaviour: An International Research Review 3 (3): 251-262. https://doi.org/10.1002/cb.138.

Reed II, Americus, Mark R. Forehand, Stefano Puntoni, and Luk Warlop. 2012. "Identity-based Consumer Behavior." International Journal of Research in Marketing 29 (4): 310-321. https://doi.org/10.1016/j.ijresmar.2012.08.002.

RSPH, 2017. \#StatusofMind. Accessed May 29, 2021. https://www.rsph.org.uk/ourwork/campaigns/status-of-mind.html

Shropshire Star 2019. Young Girls Feeling Pressure of Social Media, Study Finds. Accessed May 29, 2021. https://www.shropshirestar.com/news/uk-news/2019/03/21/young-teenage-girls feeling-pressure-of-social-media-study-finds/.

Simmel, Georg.1957. "Fashion." American Journal of Sociology 62 (6): 541-558. https://doi.org/10.1086/222102.

Turkle, Sherry. 2017. Alone Together: Why We Expect More from Technology and Less from Each Other. London: Hachette UK.

Twenge, Jean M. 2017. IGen: Why Today's Super-Connected Kids are Growing Up Less Rebellious, More Tolerant, Less Happy and Completely Unprepared for Adulthood-and What That Means for the Rest of Us. New York: Simon and Schuster.

Twenge, Jean M. 2013. "The Evidence for Generation Me and against Generation We." Emerging Adulthood 1 (1): 11-16. https://doi.org/10.1177\%2F2167696812466548. 
Van Gennep, Arnold. 2019. The Rites of Passage. Chicago: University of Chicago Press.

Woodward, Sophie. 2009. "The Myth of Street Style." Fashion Theory 13 (91): 83-101. https://doi.org/10.2752/175174109X381355.

Woodward, Sophie. 2008. "Digital Photography and Research Relationships: Capturing the $\begin{array}{lcc}\text { Fashion } & \text { Moment". } & \text { Sociology } \\ \text { https://doi.org/10.1177\%2F0038038508094566 }\end{array}$

$42 \quad(5):$

857-872. https://doi.org/10.1177\%2F0038038508094566.

Woodward, Sophie. 2007. Why Women Wear What They Wear. Oxford: Berg.

\section{ABOUT THE AUTHOR}

Naomi Joanna Braithwaite, Senior Lecturer in Fashion Management, Marketing and Communication, School of Art and Design, Nottingham Trent University, Nottingham, United Kingdom. 